\title{
Striking A Balance Between Prevention Of COVID-19 And The Promotion Of Child And Adolescent Mental Health: A Case Study Of Long Closure Of Schools In Malawi
}

\author{
Precious Makiyi
}

Genius Intellectual Consultancy

\section{Introduction}

The Corona Virus Disease-2019 (COVID-19) has necessitated the long closure of academic institutions in most countries including Malawi. By the first week of April 2020, 188 countries had closed down their schools, affecting over 1.5 billion young people ${ }^{1}$. As a way of curbing the spread of the pandemic, the Malawian president ordered an immediate closure of schools on 23rd March, 2020, affecting 5.3 million school-going children ${ }^{2}$. Schools remained closed up to August, 2020. This may have negative implications on the mental health of school-going children, adolescents and the country's economy. This commentary aims to argue against the long closure of the schools. It is not the intention of the author to demean the efforts being made towards fighting the COVID-19 pandemic. However, there is need to strike a balance between the precautionary measures and the psychosocial development of children and adolescents.

\section{COVID-19 Situation in Malawi}

Malawi registered her first three cases of COVID-19 on the 2nd April, 2020. As of the 10th August, 2020, the Ministry of Health $(\mathrm{MOH})$ announced that cumulatively, the country had registered 4,674 cases with 2,098 active cases, 2,430 recoveries and 146 deaths. The age range for the cases was 1 month to 93 years with an average of 36.7 years $^{3}$. A total of 34,877 tests were done, from which $13.4 \%$ were positives with a $52 \%$ recovery rate and a $3.1 \%$ case fatality rate. Some experts have argued that the country has not been doing enough testing, however, the available data shows that the situation in Malawi is not as bad as in other countries and may not warrant closure of schools when life has been going on as usual with markets and religious places operating as usual. One would argue that, the same children who were being barred from attending schools were freely going to other riskier places like markets and political campaign rallies, where physical distancing was totally impossible, and other preventive measures were not easily followed.

\section{School Closure: Impact on child and adolescent mental health (CAMH), Loss of Academic Potential and Economic Productivity}

According to the World Health Organization (WHO), mental health is "a state of well-being in which an individual realises his or her potential, can cope with normal stresses of life, can work productively and fruitfully, and is able to make a contribution to his or her community"4. It therefore, does not require rocket-science to realise that the COVID-19 could make it harder for individuals, including children and adolescents, to realise their potential or to be productive. With the rising cases of COVID 19, there is widespread fear and stress. Children and adolescents are at increased risk of worry, fear and anxiety ${ }^{5}$. A study done in China on the relationship between COVID-19 and youth mental health showed that about $40 \%$ of the participants were prone to mental health problems with $14.4 \%$ of them having posttraumatic stress disorder (PTSD) symptoms ${ }^{6}$. It has to be noted that according to studies, PTSD affects the frontolimbic system leading to poor emotional regulation and development ${ }^{7}$.

Young people with underlying mental illness have been more disadvantaged and are at an increased risk of relapse of their mental illness 5 . Furthermore, they are at risk of COVID-19 infection because of an impaired cognition thus, they might not practice self-care. As schools remain closed due to the pandemic, children and adolescents with mental health needs may not get some of the mental healthpromoting services they used to get while in schools. In Malawi for instance, through the school feeding program, children are supplied with nutritious porridge which is essential for healthy brain development. The closure of schools may lead to malnourishment of such beneficiaries. One Malawian primary school girl , quoted by World Food Program complained that "with schools closed, I miss school meals, sports and the health counselling sessions we used to get from mother groups after school"'. A survey done by YouthMinds in the United Kingdom involving 2,111 young people with a history of mental illness indicated that $83 \%$ of them reported that COVID-19 made them worse and about $26 \%$ were unable to access mental health support service like peer support groups ${ }^{8}$. According to a clinical psychologist working in China, where schools closed earlier, some children and adolescents locked up themselves for weeks depriving themselves of basic needs and self-help care ${ }^{1}$. It is believed that those with depression will experience adaptive problems when schools open.

The closure of schools has not spared children with special needs or developmental disorders like autism spectrum disorders (ASD), attention deficit hyperactivity disorder (ADHD) and learning disorders. For instance, children with ASD are used to daily routines hence with the closure of schools, their daily routine has been disrupted hence they might end up being aggressive and anxious ${ }^{1}$. More so, because children with developmental disorders have deficits in some 
domains of development, cessation of schools means they may not easily access services like speech therapy, social and adaptive skills training. The use of face masks is crucial for the prevention of the spread of the corona virus, however, people do not easily see each other's facial expression when putting on a mask ${ }^{7}$. This might potentially lead to deficit in socials skills development among children so much that they might not be able to attain the required skills for their survival.

During pandemics, it is quiet common for children to experience child abuse, neglect and exploitation ${ }^{1}$.The COVID-19 has led to increase in gender-based violence, teen pregnancies and child marriages. A report from Malawi's Ministry of Gender, Community Development and Social Welfare indicates that from March 2020, the country has recorded over 44,874 cases of teen pregnancies and 12,995 child marriages ${ }^{9}$. Furthermore, the Ministry of Health $(\mathrm{MOH})$ reports that in 2020, teen pregnancies increased by $35 \%$ from the previous year (10). As much as these two problems have been there before, COVID 19 and the subsequent closure of schools has influenced such an increase.

The closure of schools coupled with social isolation means children and adolescents have to be at home most of the times. If the home environment is not safe, their mental health could be in jeopardy. In China, for instance, it has been reported that cases of gender-based violence (GBV) have increased by $300 \%$ during the COVID-19 pandemic ${ }^{11}$. In Malawi, the situation is not different. For example, Thyolo district social welfare office reported that the district recorded many cases of GBV during the period the schools were closed and most of the cases were of forced marriages and unwanted pregnancies among young girls ${ }^{12}$.

Effective coping skills have been shown to protect individuals from developing mental health problems during pandemics ${ }^{6}$ however, children and adolescents, as a vulnerable group of people, tend to use negative coping styles like use of alcohol and substances as well as sexual relationships leading to addictive behaviors and poor mental health ${ }^{6}$. Studies have shown a relationship between psychological distress such as depression and anxiety with use of negative coping skills during pandemics ${ }^{6,7}$. It is therefore not surprising that the incidence of alcohol and substance abuse may have increased among the youth during the COVID-19 pandemic.

As schools remain closed, children and adolescents who have access to the internet are more likely to spend more time on the internet or on social media to be precise. This eventually increases their risk of experiencing mental health problems ${ }^{7}$. For example, increased use of the internet has been associated with depression in the United States of America and the Netherlands ${ }^{13}$. The American Academy of Pediatrics coined a new term called "Facebook depression" which is defined as depressive symptoms which occurs among teens and preteens as a result of spending much time on Facebook ${ }^{13}$. The prevalence of 'Facebook depression' may surge due to the long closure of schools.

Another point to consider on the long closure of schools is the loss of academic potential by the time schools open. It has been shown that holidays have the potential to interfere with the rhythm of learning leading to loss of knowledge and skills among learners ${ }^{14}$. A study to investigate learning losses during a nine-week summer vacation among lower secondary school students in Australia found that after the holiday, there were significant losses in arithmetic problemsolving and spellings but gains in reading ${ }^{14}$. A meta-analysis on the effects of summer vacation on achievement test scores indicated that academic performance drops during summer vacations regardless of gender or race ${ }^{15}$. The review found the same results found in Australia that summer breaks largely affect students' math skills and spellings. Interestingly, this effect is more pronounced among learners from low socioeconomic families ${ }^{15}$. "The finding that subject area influenced the amount of summer loss may be due to the differential availability of opportunities to practice different academic material over summer (with reading practice more available than math practice) and to differences in the material's susceptibility to memory decay (with factual and procedural knowledge more easily forgotten than conceptual knowledge)"15. Since the closure of schools due to COVID 19 is longer than a mere summer vacation, it is more likely that the impact could be more detrimental. For instance, the Save the Children organization has projected that by the time schools will be opened, about 10 million children in developing countries are likely not to return to school ${ }^{16}$. According to the Save the Children, the world is heading towards a global education emergency ${ }^{16}$.

As a way of curbing the effects of the holiday on academic performance, the Malawi government introduced online and radio lessons however, only $5 \%$ of Malawians have access to facilities of information and communication technology $(\text { ICT })^{2}$ and $45 \%$ of the households have radios. Unfortunately, this may bring inequalities and possibly increase the gap between the poor and the rich because only the rich can afford to access online lessons. This is in agreement to an observation by the review above that the poor are largely affected by holidays because they do not have access to extra lessons during vacations.

A country's wealth is a function of the human capita, physical assets and the natural capita. The human capita, as measured by the human development index (HDI), is derived by among other things, the average number of years that citizens spend schooling ${ }^{17}$. A study done in over 60 developing countries revealed that a one-year loss in education is equivalent to a $6.5 \%$ loss in future income ${ }^{18}$. By inference, if few individuals are educated or if the average number of years spent in school is lesser, the country's economy will be negatively affected. Thus, if schools remain closed for a long period of time, many students will drop out of school and this has implications on the country's HDI which is already low (0.485) - ranked 172 of 189 countries $^{19}$. Since early childhood development (ECD) centers are also closed due to COVID 19, millions of children might not have a good foundation, jeopardizing their early childhood development and mental health.

Finally, having explored the negative impact of the long closure of schools on children and adolescents' mental health $(\mathrm{CAMH})$, it is imperative to note that the school closure might also have positive impact on CAMH. A study in the UK suggested that the school closure led to an overall reduction in anxiety and an improved wellbeing in children between 13 and 14 years $^{20}$. We did not find a study done in developing countries looking at the positive impact of school closure on CAMH however, plausible explanation to the findings in the UK study is that during the lockdown, children were not subjected to school-related stressors like bullying and negotiating relationships with peers and 
teachers ${ }^{20}$. However, this might not be the case in settings like Malawi where in some situations, the school environment is better and offers mental health promoting activities than the home environment. The closure has also provided children with adequate time to rest and refresh, which is good for their mental health. However, the negative impact outweighs the positives.

\section{The way forward: Future Considerations of CAMH in pandemic management}

It is a known fact that COVID 19 is not the last pandemic to hit the human race, nor is it the last pandemic to necessitate closure of schools. However, looking ahead, there are a few lessons we can learn from this pandemic. A recent predictive model suggests that closure of schools would only prevent $2-4 \%$ of COVID 19 deaths $^{21}$. The Lancet series on child and adolescent health published a systematic review on school closure and management practices during the coronavirus outbreaks which concluded that it is still unclear if school closure is an effective measure against the spread of COVID $19^{21}$. For future pandemics, closing down of schools should therefore be a last resort because of its longterm consequences on the individual leaners and the nation. A lesson from west Africa on the Ebola outbreak is that even before the pandemic was eradicated, schools opened up and with proper precautionary measures, the pandemic was still under control and no surge of Ebola cases was reported $^{18}$. With the closure of medical and nursing schools, it means government may struggle to recruit more health workers. Thus, it might be difficult to fight any pandemic in such a situation. Leaving schools open while observing all necessary measures like physical distancing and practicing hygienic practices is likely to help. Instead of universal school closure, perhaps government can target schools in hotspots and schools with registered active cases. Now that the ministry of education has permitted schools to open, the school environment can be made safe for the learners and the teachers by adhering to the guidelines set by the $\mathrm{MOH}$, WHO and UNICEF.

\section{References}

1. Lee J. Mental health effects of school closures during COVID-19. Lancet child Adolesc Heal [Internet]. 2020;4(6):421. Available from: http://dx.doi.org/10.1016/S2352-4642(20)30109-7

2. Thawani F (World FP. My biggest fear is coronavirus will keep the schools closed. Insight-World Food Program [Internet]. 2020 Jun 24 [cited 2020 Aug 12]; Available from: insight.wfp.org/malawimy-biggest-fear-is-coronavirus-will-keep-the-schools-closedad8615a94dc2?gi $=$ a52 $\mathrm{f} 8417698 \mathrm{c}$

3. Ministry of Health Malawi. Covid-19 Situation Update As of 10th August 2020 [Internet]. Lilongwe; 2020. Available from: www.health. gov.mw

4. World Health Organization. WHO urges more investments, services for mental health [Internet]. 2020 [cited 2020 Oct 1]. Available from: https://www.who.int/mental_health/who_urges_investment/ en/\&grqid=a TyGT_pm\&hl=en-MW

5. Kontoangelos K, Economou M, Papageorgiou C. Mental Health Effects of COVID-19 Pandemia: A Review of Clinical and Psychological Traits. Pychiatry Investig. 2020;17(6):491-505.

6. Liang L, Ren H, Cao R, Hu Y, Qin Z, Li C. The Effect of COVID-19 on Youth Mental Health. Psychiatr Q. 2020;(91):841-52.

7. Benjamin S, Lachal J, Radjack R. Adolescent psychiatric disorders during the COVID-19 pandemic and lockdown. Psychiatry Res. 2020;(291).
8. YoungMinds. Coronavirus : Impact on young people with mental health needs. london; 2020.

9. Ministry of Gender CD and SW. A Rapid Assessment Study Of Teenage Pregnancies And Child Marriages During COVID 19 In Malawi. Lilongwe; 2020.

10. Davies P. Teen Pregnancies Rise in Malawi Amid Coronavirus Pandemic. African News [Internet]. 2020 Sep 4; Available from: https:// www.africanews.com/2020/09/04/teen-pregancies-rise-in-malawiamid-coronavirus-pandemic//\&hl=en-MW

11. 00Plan International. Living under lockdown. United Kingdom; 2020 .

12. CRECCOM. Thyolo District Social Welfare Office to Combat GBV during COVID-19 Era. 2020 Jun 29; Available from: https://www. creccommw.org/2020/06/30/thyolo-district-social-welfare-office-tocombat-gvb-during-covid-19-era/\&hl=en-MW

13. O'keeffe GS, Clarke-Pearson K, Media C on C and. Clinical Report - The Impact of Social Media on Children, Adolescents, and Families abstract. Pediatrics. 2011;127(800).

14. Paechter M, Luttenberger S. The Effects of Nine-Week Summer Vacation : Losses in Mathematics and Gains in Reading. Eurasia J Math Sci Technol Educ. 2015;11(6):1339-413.

15. Cooper H, Nye B, Charlton K. The Effects of Summer Vacation on Achievement Test Scores : A Narrative and Meta-Analytic Review. Rev Educ Res. 1996;66(3):227-68.

16. Wagner, Warren E, Hollie. Save Our Education: Protect Every Child's Right to Learn in the COVID-19 Responce and Recovery [Internet]. 2020. Available from: https://www.resourcecentre.savethechildren.net/ library/save-our-education

17. Sagar AD, Najam A. The Human Development Index : A Critical Review. Ecol Econ. 1998;(25):249-64.

18. Selbervik H. Impacts of School CLosure on Children in Developing Countries: Can we learn something from the past? [Internet]. Chr. Michelsen Institute. 2020 May. Available from: https:/www.cmi. no/publications/7214-impacts-of-school-closures-on-children-indeveloping-countries-can-we-learn-something-from-the-past\&hl=enMW

19. UNDP. Inequalities in Human Development in the 21 st Century: Malawi. 2019.

20. Widnall E (University of B. School clossures had Positive Effects on Some Teenagers' Mental Health, Our New Research Suggests [Internet]. The Conversation. 2020 [cited 202AD Sep 23]. Available from: https://www.theconversation.com/school-closures-had-positiveeffects-on-some-teenagers-mental-health-our-new-research-suggests$144884 \&$ hl $=$ en-MW

21. Viner R, Russell Si, Croker H, Packer J. School Closure and Management Practices during Coronavirus Outbreaks Including COVID-19: a Rapid Systematic Review. Lancet Child Adolesc Heal. 2020;4(5):397-404.

22. National STatistical Office. Survey On Access and USage of ICT Services in Malawi. June 2015 